DOI: 10.12957/demetra.2016.21374

\title{
Programa Bolsa Família: perfil, ações intersetoriais e percepção dos gestores de serviços, em um estudo de caso nos Morros de Santos
}

\section{Bolsa Família Program: profile, intersectoral actions and perceptions of service managers, in a Case Study in Morros de Santos, Brazil}

Luana Pereira Lima'

Lia Thieme Oikawa Zangirolani'

1 Universidade Federal de São Paulo, Departamento de Políticas Públicas e Saúde Coletiva. Santos-SP, Brasil.

Correspondência / Correspondence Lia Thieme Oikawa Zangirolani Departamento de Políticas Públicas e Saúde Coletiva, Universidade Federal de São Paulo UNIFESP - Santos-SP, Brasil.

E-mail:liaoikawa@gmail.com

\section{Resumo}

O Programa Bolsa Família (PBF) é um exemplo de ação que demanda esforços intersetoriais e contribui para implantação do Sistema de Segurança Alimentar e Nutricional (SISAN) no país. Tem como beneficiários, famílias em situação de maior vulnerabilidade, tendo de enfrentar a complexidade desta condição. Nesse sentido, a intersetorialidade é a estratégia política que tem sido orientada pelas principais Políticas Públicas no Brasil. Trata-se de um estudo de caso, nos Morros de Santos, que objetivou caracterizar o perfil dos beneficiários do PBF, mapear e refletir sobre as ações intersetoriais implantadas ou em construção e conhecer a percepção dos gestores locais sobre o programa. Para tanto, utilizou questionário e entrevista semiestruturada para coleta de dados. O perfil foi traçado por análise descritiva e as entrevistas foram analisadas por análise de conteúdo. Foram entrevistados cinco informantes-chave dos serviços de assistência social, saúde e educação dos Morros de Santos. O perfil dos beneficiários se coaduna aos objetivos do programa, mas não há acesso dos serviços a informações unificadas. As ações têm se restringido ao acompanhamento setorizado das condicionalidades do PBF. A percepção dos gestores sobre o programa é de que ele cumpre seus objetivos, apesar de ainda não ser visto como um direito. Diante desse cenário, sugere-se o investimento municipal nos diferentes setores, repensando a política das ações, considerando a intersetorialidade como eixo estratégico. Ter um sistema de informação unificado viabilizaria o trabalho e a efetivação dessas ações, inclusive as promotoras de SAN, contribuindo diretamente na implantação e consolidação do SISAN no município.

Palavras-chave: Política Social. Segurança Alimentar e Nutricional. Intersetorialidade. Estudo de caso. Ação Intersetorial. 


\section{Abstract}

The Bolsa Família Program - PBF is an example of action that requires intersectoral efforts and contributes to implementation of the Food Safety System and Nutrition - SISAN. Beneficiary families are in the most vulnerable situation, as they have to face the complexity of this condition. In this sense, the intersectoral approach is the political strategy that has been used by the main public policies in Brazil. This is a Case Study in Morros de Santos, which aimed to characterize the profile of PBF beneficiaries, map and reflect on the intersectoral actions implemented or under construction and to gather information on the perception of service managers about the program. Therefore, questionnaire and semi-structured interviews were used to collect data. The profile has been defined by descriptive analysis and interviews were analyzed by content analysis. Five key informants of social, health and education services of Morros de Santos were interviewed. The profile of the beneficiaries was in line with the program objectives, but there is no access of services to unified data. The actions have been restricted to sectored monitoring of PBF's conditionalities. The perception of managers about the program is that it fulfills its objectives, although it is not yet seen as a right. In this scenario, it is suggested that municipal investment should occur in different sectors, while rethinking policy actions and considering intersectorality as an strategic axis. Having a unified information system would facilitate the work and the effectiveness of these actions, including promoting SAN, thus contributing directly to the implementation and consolidation of SISAN in the city.

Key words: Public Policy. Food and Nutrition Security. Intersectoral Action. Case Studies. Intersectoral Action.

\section{Introdução}

Quase 10 anos após a I Conferência Nacional de Segurança Alimentar e Nutricional (I CNSAN) é que o combate à fome passou a ser considerado pauta prioritária da agenda política no Brasil. ${ }^{1}$

Em 2003, início do governo Lula, foi lançado o Fome Zero, estratégia para assegurar o Direito Humano à Alimentação à população brasileira. Esta estratégia teve como base a articulação de políticas, programas e ações, visando garantir acesso à alimentação às pessoas, sobretudo, àquelas em situação de pobreza e extrema pobreza. ${ }^{2}$ É nessa conjuntura que, em 2004, foi criado o Programa Bolsa Família, que unificou programas nacionais de transferência direta de renda, tendo como foco o combate à fome e à pobreza no país. ${ }^{3}$ 
A estratégia Fome Zero é um marco dos avanços ocorridos no país nesse período, como a instituição da Lei Orgânica de Segurança Alimentar e Nutricional (LOSAN), Lei no 11.346/2006, que cria o Sistema Nacional de Segurança Alimentar e Nutricional (SISAN), com vistas a assegurar a alimentação adequada como direito humano e responsabiliza o poder público por políticas e ações que assegurem a Segurança Alimentar e Nutricional ${ }^{a}$ (SAN) da população.,3-7

O SISAN estimula a intersetorialidade, incentivando a integração de esforços entre governo e sociedade civil, para a implantação de políticas promotoras de SAN e também para o seu monitoramento e avaliação no país, numa perspectiva de complementaridade e otimização das potencialidades de cada setor. ${ }^{5}$

De âmbito federal, com mais de uma década de implantação, o Programa Bolsa Família (PBF) é um exemplo de ação que demanda esforços intersetoriais e contribui para implantação do SISAN no país.

Por ser um programa que tem como beneficiários as famílias em situação de pobreza e pobreza extrema, tem de enfrentar a complexidade destas condições, que são consequentes não só da insuficiência de renda, mas também da insegurança alimentar e nutricional, da baixa escolaridade, da pouca qualificação profissional, da fragilidade de inserção no mercado de trabalho, do acesso precário à saúde e à moradia, entre outros fatores determinantes. ${ }^{8,9}$

Para tanto, o programa tem três eixos principais: a transferência de renda para promover o alívio imediato da pobreza; as condicionalidades para reforçar o acesso aos direitos sociais básicos de educação e saúde; e as ações e programas complementares criados pela Assistência Social, que buscam desenvolver as famílias, para que estas possam superar a situação de vulnerabilidade. Para além de ter como objetivo básico e estratégico promover a intersetorialidade e complementaridade das ações sociais públicas, o governo tem a responsabilidade de ofertar serviços públicos de saúde, educação e assistência social com qualidade, enquanto as famílias devem assumir compromissos para continuar recebendo o benefício. ${ }^{10}$

A intersetorialidade é uma estratégia política que está relacionada diretamente à ampliação do envolvimento social, que compreende a participação dos usuários, profissionais e gestores dos diversos setores para a implementação e execução de projetos e programas, cuja lógica de atuação deve ser voltada à população e ao território onde se encontra. Desse modo, é possível identificar tanto os problemas como as possibilidades de solução, considerando as particularidades..$^{11,12}$

a "Segurança Alimentar e Nutricional é a realização do direito de todos ao acesso regular e permanente a alimentos de qualidade, em quantidade suficiente, sem comprometer o acesso a outras necessidades essenciais, tendo como base práticas alimentares promotoras de saúde que respeitem a diversidade cultural e que sejam ambiental, cultural, econômica e socialmente sustentáveis" (LOSAN, 2006). 
A intersetorialidade pode ser compreendida como uma ação que permite interação, comunicação e compartilhamento de saberes em torno de metas ou objetivos comuns. Portanto, tem por alicerce uma lógica que transcende um único setor da política social, tendo como paradigma norteador a otimização de saberes, competências e relações, em prol de um objetivo comum, com prática social compartilhada, e que requer planejamento e avaliação para realização de ações mais eficientes em responder às demandas ou necessidades dos cidadãos. ${ }^{13-15}$

Por se tratar de uma estratégia política, traduz-se em um processo desafiante, que pode se deparar com empecilhos político-administrativos, socioeconômicos, contextos regionais e opiniões divergentes entre os atores envolvidos. Para o sucesso das ações intersetoriais, é importante que estejam em constante construção, necessitando determinação e empenho, exigindo capacidade de negociação e flexibilidade para contornar e resolver conflitos, ao mesmo tempo, respeitando as particularidades. ${ }^{11,16}$

Segundo relatório do Instituto de Pesquisa Econômica Aplicada (IPEA), ${ }^{17}$ nos últimos 20 anos o aumento de renda das famílias, a expansão dos serviços de saúde e de vigilância nutricional, a elevação do nível educacional das mães, a melhoria das condições de saneamento e articulação intersetorial de programas sociais têm sido importantes para a melhoria de segurança alimentar da população.

Após dez anos de PBF, são atendidas 13,8 milhões de famílias, cerca de 50 milhões de pessoas recebendo o benefício com valor médio de $\mathrm{R} \$ 152,00$. O programa tem grande impacto na vida econômica e social do país, e indicadores mostram que o programa é responsável por 19,4\% da redução da mortalidade infantil, 79,9\% de aprovação dos estudantes do PBF e 7,1\% de abandono de sala de aula enquanto a média nacional é de $10,8 \%$. $^{2,13}$

Consolidar a ideia de que trabalhar regional ou localmente nas políticas públicas, construindo de forma coletiva uma rede de colaboração entre as ações sociais, mesmo compreendendo que a intersetorialidade não é garantia automática de desenvolvimento social, mas que pode colaborar na promoção de inclusão e redução da vulnerabilidade social, tem sido uma das principais orientações das políticas de assistência social, SAN e saúde no Brasil. ${ }^{18}$

Desse modo, este estudo se propõe a caracterizar o perfil dos beneficiários do Programa Bolsa Família dos morros Nova Cintra, Vila Progresso e Santa Maria, mapear e refletir sobre as ações e/ou mecanismos intersetoriais que vêm sendo construídos e/ou realizados, ou não, no sistema público de saúde, educação e assistência social desse território e conhecer a percepção dos gestores locais sobre o programa, com vistas a contribuir para os esforços de articulação que pretendem melhorar a SAN da população beneficiária do PBF, em Santos, por meio da implantação e consolidação do SISAN. 


\section{Método}

De acordo com o Instituto Brasileiro de Geografia e Estatística, ${ }^{19}$ Santos se caracteriza por ser a 10 a maior cidade do Estado de São Paulo, com população estimada em mais de 430 mil habitantes para 2013, além de ser também a 17ª cidade mais rica do país, com um PIB da ordem de R \$ 44,4 bilhões em 2013. ${ }^{20}$ Em 2013, o Estado de São Paulo registrou a Taxa de Mortalidade Infantil de 11,5 óbitos por mil nascidos vivos e o Departamento Regional de Saúde da Baixada Santista registrou um dos índices mais elevados, 18,1 óbitos por mil nascidos vivos. ${ }^{21-24}$

O Plano Diretor da cidade de Santos divide o município em duas áreas, denominadas insular e continental. A área insular concentra 99,3\% da população e é composta por quatro regiões: Morros, Central histórica, Zona Noroeste e Zona da Orla-Intermediária. ${ }^{19}$

A região dos Morros, em particular, é caracterizada por 16 morros, com ocupação bastante heterogênea, incluindo áreas de ocupação residencial e também comercial, habitações precárias e também condomínios fechados e loteamentos de baixa densidade populacional. O contexto dessa região coloca um número significativo de pessoas vivendo em situação de risco e vulnerabilidade social, tornando-se relevante a discussão sobre a presença do Estado e de políticas públicas para garantia de boas condições de vida e saúde nesse território. ${ }^{25}$

As características da cidade de Santos levaram à inserção de ações de ensino, pesquisa e extensão da Universidade Federal de São Paulo campus Baixada Santista (UNIFESP-BS) em regiões de maior vulnerabilidade social, entre elas, a região dos Morros. Esta inserção foi o ponto inicial da construção da articulação ensino-serviço que vem sendo construída e aprimorada ao longo dos anos, entre a UNIFESP-BS e a Prefeitura de Santos, permitindo, além da qualificação da atenção prestada aos cidadãos, também a criação de vínculo com as equipes de saúde, educação e assistência social desses territórios.

Em relação ao sistema público de educação, saúde e assistência social, a região dos Morros de Santos conta com cinco Unidades Básicas de Saúde (UBS), quatro Unidades de Saúde da Família (USF), dois Centros de Referência de Assistência Social (CRAS), cinco Unidades Municipais de Ensino (UME) do $1^{\underline{0}}$ ao $5^{\underline{0}}$ ano e duas UME do $6^{\underline{0}}$ ao $9^{\underline{0}}$ ano. ${ }^{26,27}$

A vulnerabilidade social dessa região, a inserção de ações de ensino, pesquisa e extensão da UNIFESP-BS nessas áreas e a existência de serviços públicos de educação, saúde e assistência social no território justificam a escolha dos morros como lócus para o desenvolvimento deste estudo.

Para atender aos objetivos propostos, foi desenvolvido um estudo de caso nos morros Nova Cintra, Vila Progresso e Santa Maria, em Santos.

Segundo YIN, ${ }^{28}$ a preferência pelo estudo de caso deve ser dada quando os comportamentos relevantes não podem ser manipulados, mas é possível fazer observações diretas e entrevistas. 
Trata-se, ainda, de um método que oferece várias estratégias de investigação qualitativa que permitem mapear, descrever e analisar o contexto, as relações e as percepções a respeito do caso em questão. Permite, também, maior proximidade com os atores envolvidos, que podem trazer colaborações significantes para o conhecimento do fenômeno ou episódio em estudo. ${ }^{29-32}$

Neste sentido, foram utilizadas múltiplas fontes de informação, revisão bibliográfica, entrevista semiestruturada, questionário estruturado e análise de documentos ou dados consolidados.

A revisão bibliográfica foi feita em bases de dados indexadas como o Scielo, MedLine e PubMed, utilizando os seguintes descritores, de forma isolada e combinada: Políticas Públicas; Programa Bolsa Família; Programa Fome Zero; Intersetorialidade; Segurança Alimentar e Nutricional; Transferência de renda. Também foram consultados documentos oficiais, publicados no período de 2003 a 2015. Esta revisão permitiu fundamentar e aprimorar não só a construção dos instrumentos da pesquisa como também o aprofundamento teórico para a análise dos resultados.

A elaboração do roteiro da entrevista semiestruturada partiu de questionamentos elementares, apoiados em teorias e hipóteses relevantes para a pesquisa. As entrevistas foram conduzidas de maneira informal, permitindo aos entrevistados discorrer sobre o assunto, conforme recomendado na literatura. 27,31

Estas foram realizadas nos morros Nova Cintra, Vila Progresso e Santa Maria. Foram considerados informantes-chave desta pesquisa, os gestores locais dos serviços públicos de saúde, educação e assistência social de referência nesse território.

Para a seleção dos serviços de educação, foi feita uma consulta ao setor de saúde, que indicou duas unidades de ensino do território, com o critério de serem as unidades com a maior concentração de crianças beneficiárias do PBF matriculadas.

Já a escolha do Centro de Referência em Assistência Social (CRAS) e das Unidades de Saúde deu-se em virtude de serem os serviços de referência do território sob estudo.

Para a elaboração do roteiro da entrevista semiestruturada, realizou-se um estudo piloto do instrumento, que, segundo YIN, ${ }^{28}$ é um passo fundamental, pois ajuda o investigador a refinar a sua pesquisa, aumentando as chances de sucesso no estudo proposto. O estudo piloto foi conduzido no CRAS do morro São Bento, em Santos, por atender à região próxima e com características semelhantes aos morros onde o estudo foi conduzido.

Por meio do estudo piloto, identificou-se a necessidade de ajustes no roteiro, tanto no que se refere à forma e à linguagem, como na sequência de questões e no tempo da entrevista. Foram feitos os ajustes necessários de nomenclatura, modificação na ordem das questões, aprimoramento textual visando à objetividade e à melhor interpretação das questões do roteiro da entrevista semiestruturada. 
Após o estudo piloto, entrevistou-se os gestores dos serviços de Saúde, Educação e Assistência Social.

Para responder ao primeiro objetivo, foram coletados dados concretos, por meio de um questionário com questões fechadas, que possibilitou a coleta de informações sobre o perfil dos beneficiários do PBF. As questões foram construídas a partir das finalidades do estudo e dos dados obrigatórios para o cadastramento no Cadastro Único (CadÚnico).

A análise de documentos se deu nos casos em que o entrevistado considerou necessário fazer alguma consulta para responder às questões da entrevista ou do questionário, garantindo a precisão da informação.

Para a análise das questões fechadas, foi utilizada a estatística descritiva simples, por ser uma técnica de análise de dados aplicável aos objetivos deste estudo. ${ }^{33-35}$

Para responder ao segundo e terceiro objetivos, fez-se a apreciação das questões abertas, por meio de análise de conteúdo, que se constitui de técnicas capazes de organizar e descrever o conteúdo emitido no processo de comunicação, permitindo a qualificação das vivências e do conhecimento dos sujeitos evolvidos, bem como suas percepções sobre fenômenos ou determinados objetos. ${ }^{36-38}$

Para tanto, todas as entrevistas tiveram o áudio gravado e transcrito, conservando tanto o registro da palavra como dos silêncios, risos, repetições, lapsos e sons, conforme metodologia proposta por Minayo. ${ }^{28,33}$

A transcrição foi feita duplamente, para garantir não só a precisão das informações, mas também aspectos que compreendem a interpretação e a fidelidade dos dados, visto que a falta de exatidão pode levar à descontextualização, provocando erro ou imprecisão na compreensão do conteúdo, em parte ou em sua totalidade. ${ }^{34}$ Para garantir a confidencialidade das informações, foram atribuídos códigos aos entrevistados, foi utilizada a letra "g" de gestor, seguida de numeração sequencial para identificá-los.

A organização e categorização dos conteúdos deram-se inicialmente pela leitura flutuante do conteúdo das entrevistas, para estabelecer um primeiro contato com o material e, posteriormente, realização da escuta, leitura e releitura das transcrições exaustivamente, para organização das falas conforme o roteiro da entrevista.

Foram então formuladas hipóteses para cada questão da entrevista para melhor explicitação das dimensões e direções das análises, de forma que as falas, seus sentidos e percepções dos sujeitos pudessem ser codificados por critério semântico, depois organizados em unidades de registro, às quais foram atribuídos temas correspondentes aos conteúdos, agrupando-os em núcleos temáticos, e, finalmente, foram organizadas as categorias com os trechos das falas dos entrevistados, que fundamentaram a interpretação final, conforme orienta Bardin. ${ }^{38}$ 
Este estudo seguiu as normas da Resolução CNS 466/2012, sendo submetido e analisado pelo Comitê de Ética em Pesquisa da Universidade Federal de São Paulo - CEP/UNIFESP, obtendo parecer favorável à sua execução sob número 1.069.607.

\section{Resultados e Discussão}

Foram entrevistados dois gestores dos serviços de Saúde (unidades básicas de saúde), dois gestores da Educação (escolas) e um gestor do serviço da Assistência Social (CRAS), totalizando cinco entrevistas.

Na etapa de coleta dos dados do perfil dos beneficiários, os gestores relataram não haver uma sistematização para acesso a essas informações, sendo necessário consultar dados consolidados. Para tanto, fez-se a contagem manual dos dados disponíveis no Mapa de Acompanhamento do Bolsa Família, referentes ao segundo semestre do ano de 2014, que eram os mais recentes disponíveis.

As informações fornecidas pelos gestores dos serviços de saúde, assistência social e educação, dos morros Nova Cintra, Vila Progresso e Santa Maria, revelaram que o principal tipo de arranjo familiar entre os beneficiários do Programa Bolsa Família é o monoparental, ou seja, família composta por apenas um dos progenitores. Outra característica importante é que, na maioria das famílias beneficiárias, as mães é que são responsáveis pelo sustento da família e apresentam idade média entre 20 e 30 anos. Os gestores também informaram que a grande maioria dessas mães está inserida no mercado informal de trabalho e que a média de moradores por domicílio é de cinco pessoas.

Segundo Scarpellini \& Carlos, ${ }^{39}$ estudos no Brasil demonstram que as famílias chefiadas por mulheres têm crescido nas últimas décadas e correspondem a 11,1 milhões. O conceito de família monoparental foi reconhecido em 1988 com a promulgação da Constituição Federal. Famílias que têm mães como progenitoras são consideradas as mais vulneráveis no plano econômico, que têm como indicador social as necessidades básicas: educação, renda e habitação.

Este aspecto informado é compatível com aquele descrito no relatório do IPEA, ${ }^{17,40}$ que identifica no arranjo monoparental feminino, de mulheres adultas jovens, o perfil de famílias suscetíveis à situação de maior vulnerabilidade, por não poderem contar com o auxílio de outros adultos para a manutenção e cuidado com a família.

Uma característica desse território é que ele é marcado pela presença do tráfico, assim como outros territórios vulneráveis do estado e do país. Esta condição expõe as famílias que aí habitam a situações de violência e drogadição, quando não na própria família, nos arredores. Para alguns autores, que estudam os grandes centros urbanos, esta condição de moradia reafirma a conjuntura de vulnerabilidade dessas famílias, marcada pela exclusão social, desigualdade e preconceito. ${ }^{41}$ 
Foi detectada uma diferença entre os números de beneficiários do PBF cadastrados nos diferentes serviços. Os dados revelam 1.400 beneficiários do programa cadastrados nos serviços de saúde e 780 cadastrados no serviço de assistência social de referência. Os dados fornecidos pelos serviços de educação são menores, conforme o esperado, visto que este setor acompanha somente crianças matriculadas na educação infantil e fundamental I (de 5 a 12 anos de idade), totalizando 312 crianças.

Tabela 1. Beneficiários cadastrados nos serviços de saúde, por tipo de população elegível. Morros Nova Cintra, Vila Progresso e Santa Maria, Santos-SP, 2015.

\begin{tabular}{lcc}
\hline \multicolumn{1}{c}{ Tipo de população elegível } & Número de beneficiários & Proporção (\%) \\
\hline 0 a 7 anos & 493 & 35,2 \\
8 a 14 anos & 64 & 4,6 \\
15 a 17 anos & 100 & 7,1 \\
Gestantes ou nutrizes & 7 & 0,5 \\
Famílias com renda $<$ R 85,00 & 736 & 52,6 \\
per capita/mês) & & 100 \\
\hline Total & 1400 & \\
\hline
\end{tabular}

Fonte: Dados do Mapa de Acompanhamento do Bolsa Família, coletados nos serviços de Saúde dos morros Nova Cintra, Vila Progresso e Santa Maria, referentes ao segundo semestre de 2014.

Diante dos resultados encontrados, a criação de um sistema único e integrado de informação dos beneficiários do PBF seria uma estratégia intersetorial de interlocução entre os serviços, tanto para o acesso à informação por todos os serviços, facilitando o acompanhamento do cumprimento das condicionalidades, como também para o planejamento e execução de ações integradas.

Junqueira ${ }^{42}$ apresenta uma experiência de estratégia para além do cadÚnico, baseada em uma administração descentralizada e intersetorial, na qual foi implantado um projeto político com base em uma reforma administrativa. O estudo identificou que a reestruturação da administração não é uma tarefa fácil, entretanto, traz benefícios diretos para a população, como melhor qualidade de vida e maior número de cidadãos beneficiados com as ações realizadas.

A partir da organização e categorização dos conteúdos das entrevistas, foram agrupados os sentidos das falas em três núcleos temáticos: Percepção dos gestores sobre os empecilhos para o bom funcionamento do programa; Percepção dos gestores sobre a intersetorialidade e Percepção dos gestores sobre o Programa Bolsa Família. 


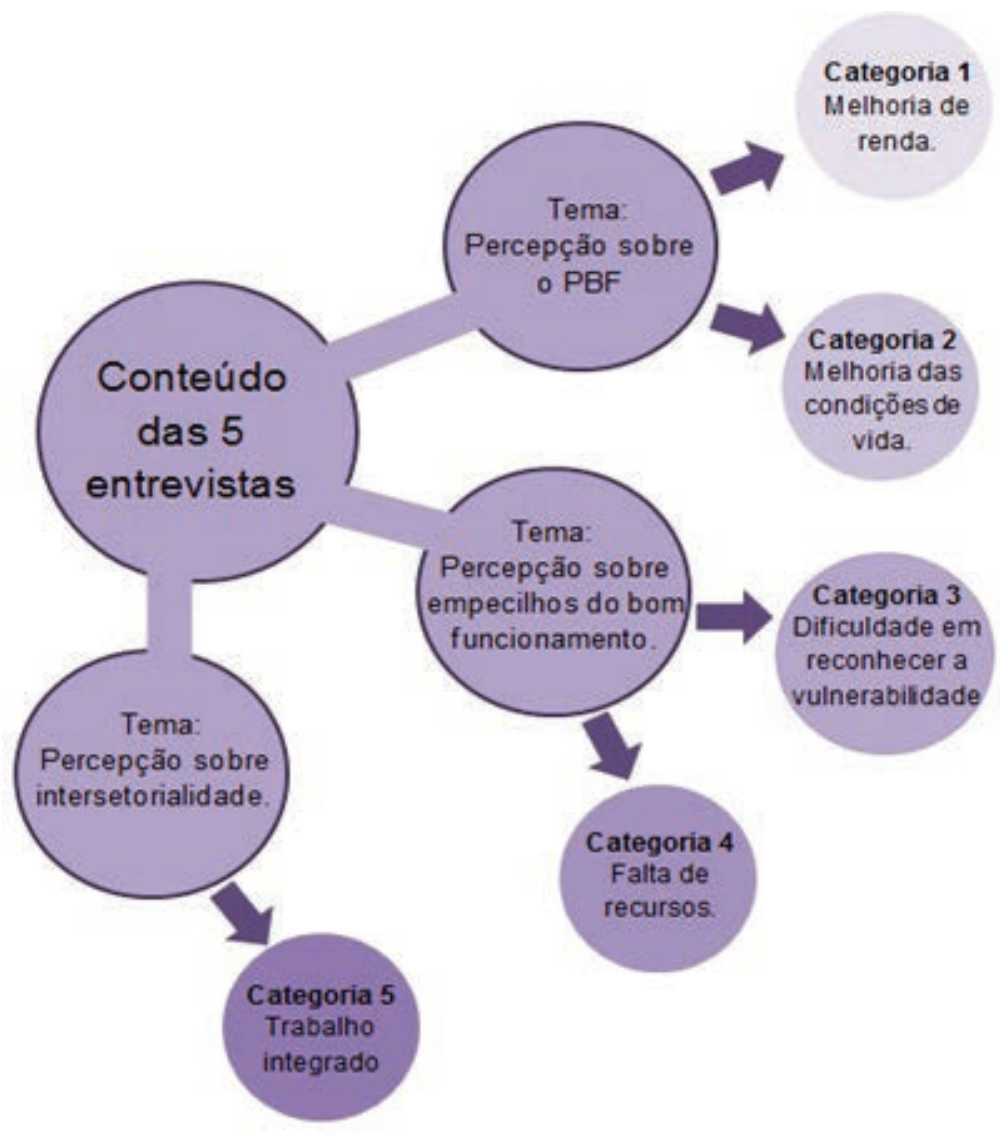

Figura 1. Modelo de organização dos núcleos temáticos e categorias, construído para análise de conteúdo das entrevistas com os gestores dos serviços. Morros Nova Cintra, Vila Progresso e Santa Maria, Santos - SP, 2015.

Quanto às ações e/ou mecanismos intersetoriais, os resultados revelam que os serviços aqui entrevistados não realizam ações ou atividades específicas para os beneficiários do PBF, a não ser o acompanhamento das condicionalidades do programa, que é feito por cada setor, sem interlocução com os demais. Atividades ou ações voltadas à promoção da segurança alimentar e nutricional (SAN) também não ocorrem especificamente para esse público.

Os obstáculos citados para a efetivação das ações intersetoriais se dão especialmente por falta de comunicação entre os setores e de infraestrutura, mesmo não havendo dúvida entre os gestores de que a intersetorialidade seria fundamental para o melhor funcionamento do programa. 
A análise de conteúdo evidencia que, na realidade, as ações para os beneficiários do programa são voltadas apenas para o acompanhamento das condicionalidades, uma vez que as ações realizadas intersetorialmente e dentro dos serviços são voltadas a toda população atendida, sem separação entre beneficiários ou não.

Para o acompanhamento das condicionalidades, os serviços realizam acompanhamento por meio de relatórios semestrais, disponibilizados pelo Ministério do Desenvolvimento Social (MDS), sendo o setor educação o responsável pelo acompanhamento da frequência escolar e a saúde, pelo acompanhamento do calendário vacinal, do pré-natal, da aferição de peso e altura, entre outros serviços competentes ao setor. ${ }^{43-45}$

O núcleo temático estruturado sobre a percepção dos gestores quanto aos empecilhos para o bom funcionamento do programa foi constituído por duas categorias:

1. A dificuldade de reconhecer a vulnerabilidade das famílias

(...) porque quando ela chega em casa e não vai ter aquele horário sossegado pra estudar, ela não vai ter [...] a professora exige que ela chega limpinha, mas acontece que ela mora em uma área de invasão e lá não tem água, ela não vai entrar limpinha dentro da sala, não vai entrar com uniforme, e alguns profissionais começam a aprender que tem que ter uma conversa de, de rede, porque ela sozinha, não dá (gl).

(...) um dos problemas mais [...], que pelo menos a gente sente várias, não só do Bolsa Família, mas como vigilância ... é a população flutuante. Que uma hora tá aqui, outra hora tá lá e geralmente a população mais carente que precisa ficar migrando de um lugar para outro, porque não consegue se manter. Essa é a nossa maior dificuldade para controle. Se a gente já tem problema de cadastro, atualizar cadastro, imagina se é uma pessoa que entra e cadastra aqui e sai daqui na semana seguinte? (g5).

\section{A falta de recursos/infraestrutura}

(...) a gente não tem recurso humano. Se eu quisesse agora fazer algum movimento de trazer o serviço X, de trazer o serviço $Y$, eu poderia estar esbarrando nessa questão... Todos os equipamentos estão com falta de recurso humano, então não tem gente disponível para estar aqui, como eu também posso não estar disponível para ir até lá, então isso pra mim é um problema... nem sempre os serviços todos conseguem estar juntos para discutir o Bolsa Família. Por quê? Porque é um convite, as pessoas precisam estar é ... abertas né, pra sair do seu serviço e ir pra esta reunião (g3).

A percepção dos gestores quanto à população flutuante, que não tem condições de se fixar no mesmo domicílio por muito tempo, explicita um fator de vulnerabilidade.

Esses resultados se somam a outros estudos, que apontam que grande parte da população paulista (52\%) vive em favelas, cortiços e loteamentos clandestinos precários, que vêm crescendo e 
ocupando desordenadamente o espaço urbano. ${ }^{45}$ Segundo os dados do Datasus, ${ }^{22-24}$ o PBF atende na cidade de Santos 5.833 famílias, de acordo com o relatório enviado pelas Unidades de Saúde, sendo apenas 55,65\% acompanhadas por essas unidades. Dos beneficiários, 573 famílias não residem no local indicado para a realização da busca ativa e para a continuidade do acompanhamento.

De acordo com Pettengill \& Angelo, ${ }^{46}$ a vulnerabilidade revela-se como uma condição humana, e ao reconhecê-la no outro, o sujeito pode colocar-se em seu lugar e assim começar a entender sua condição. Enquanto isso não acontece, há maior dificuldade em distinguir a vulnerabilidade do outro.

Quanto ao observado na categoria que trata da falta de recursos e infraestrutura, como um empecilho para o bom funcionamento do programa, Lício \& Curralero ${ }^{43}$ desvelam a dificuldade dos gestores para lidar com a falta de infraestrutura, que abrange desde a falta de pessoas/profissionais para exercer o trabalho até a falta de canetas e computadores para a realização de tarefas básicas, sem contar a consequente não adesão dos gestores e/ou equipe, por falta ou número insuficiente de funcionários, gerando uma não compatibilidade entre as agendas dos serviços.

Quanto à intersetorialidade das ações desenvolvidas, os serviços mencionam como única ação desta natureza, mas não voltada exclusivamente aos beneficiários do PBF, as chamadas "reuniões de território", que ocorrem mensalmente. Nela se discutem inúmeras questões do território e, quando necessário, incluem casos de famílias beneficiárias com dificuldade de cumprir as condicionalidades.

Do conteúdo analisado emergiu a percepção dos gestores sobre a intersetorialidade como tema, constituído da seguinte categoria:

1. Intersetorialidade como trabalho integrado

Ah sim, aquela questão da gente estar trabalhando em conjunto [...], eu entenderia que seria todos os serviços que trabalham com a família, UBS, o CRAS, as escolas estar tendo encontros mensais pra poder se estar discutindo as questões das famílias e isso realmente não acontece, então é um pouco isolado (g3).

Que todos os serviços que fazem a rede de assistência seja saúde, educação e de assistência social, todos são interligados, então todos tem esse papel de acompanhar na medida do que exerce fazendo controle ( $g 5)$.

Esta valorização da intersetorialidade pelos gestores dos serviços é positiva e vai ao encontro do que autores vêm apontando como possibilidade para o melhor funcionamento do Programa Bolsa Família. Alguns estudos comprovam que o trabalho intersetorial facilita a articulação das ações entre as políticas públicas, possibilitando o melhor funcionamento do Bolsa Família.43,44

A valorização também é importante, na medida em que construir a intersetorialidade das ações, nos territórios, não é um trabalho trivial. É um processo contínuo e desafiador, requer investimento, 
planejamento, avaliação e persistência para superar dificuldades político-administrativas, econômicas, diferenças regionais, e ainda contemplar a diversidade de compreensão e opinião dos atores do processo. ${ }^{11,12,14,16}$ Portanto, a valorização revela uma percepção da potência que ações desta natureza poderiam ter.

As ações intersetoriais podem refletir na promoção de SAN, entretanto, este estudo de caso mostrou que no território estudado não são realizadas ações específicas para beneficiários do Programa Bolsa Família, apesar da intersetorialidade ser uma das principais orientações das políticas de assistência social, saúde e SAN no país. . $^{18,47}$

Contudo, os serviços de educação e assistência social citam ações setorizadas e pontuais, como a presença do nutricionista da Secretaria de Educação como promotor de saúde, por meio da alimentação escolar e de palestras educativas que são oferecidas durante o ano letivo, e o benefício eventual da cesta básica, respectivamente, como uma forma de garantia de alimentação e SAN para a população.

No que se refere à percepção dos gestores sobre o programa, as entrevistas com os gestores mostram que todos os setores têm uma boa compreensão sobre os objetivos do Bolsa Família, pelo menos quanto a dois dos seus três eixos principais: $\mathrm{o}$ alívio imediato da pobreza e as condicionalidades como meio de garantir o acesso aos serviços sociais básicos. No entanto, o terceiro eixo, que se refere às ações e/ou programas complementares com objetivo de desenvolver as famílias, para que estas possam superar a situação de vulnerabilidade, praticamente não foi citado. Apesar de alguns gestores concordarem que este tipo de ação deveria ocorrer como uma estratégia emancipadora das famílias, aparentemente, não tem sido possível ampliar este eixo do programa.

Uma grande parte dos programas complementares são desenvolvidos por ministérios setoriais, com pouco envolvimento das esferas estaduais e municipais. Santos \& Magalhaes ${ }^{48}$ revelam que não há um investimento federal específico, para a implementação dos programas complementares. Apontam, ainda, que o pouco investimento nesses programas não é característica de um local isolado, e que ainda é pouco expressiva a integração do PBF com outras políticas públicas, em função do baixo investimento e do pouco conhecimento e divulgação dos programas existentes.

Os autores ${ }^{48}$ defendem que apenas propor cursos de qualificação não promoverá a emancipação das famílias beneficiárias, uma vez que as mesmas ou não acessam as informações necessárias para realizar os cursos ou, quando o fazem, não recebem apoio para se inserir no mercado de trabalho após a conclusão. Nessa perspectiva, sugerem que as ações se voltem não só para qualificar, mas também para reinserir as famílias no mercado de trabalho, sendo necessário investir também em setores econômicos, capazes de produzir empregos e oportunidades, para, assim, promover a emancipação das famílias de maneira eficaz. 
O núcleo temático de percepção dos gestores sobre o Programa Bolsa Família agrupou duas categorias de sentido:

1. O programa como possibilidade de melhoria da renda, como pode ser observado nas seguintes falas:

Então, o, o BF é o grande programa de transferência de renda do governo federal e que [...] ganhou status de Política de Estado [...] é um programa que tirou realmente as famílias da linha da miséria e colocou com o mínimo de renda mensal (g1).

o que eu vejo dos objetivos do Bolsa Família é que ele contribui na melhoria de renda né, renda das famílias de baixa renda né... (g2).

2. O programa como possibilidade da melhoria das condições de vida:

Bom, os objetivos do PBF pelo que eu entendo é um programa maravilhoso, [...] que veio para ajudar, e eu entendo que tá aqui bem pra poder [...] suprir algumas dificuldades que essas famílias estão passando (g3).

O Bolsa Família ele veio a té para contribuir com o futuro da criança, frequentando as unidades escolares, o pai tendo uma assistência, [...] é melhorar as condições de vida das, das, das famílias carentes (g4).

São famílias que não tem condições nenhuma e precisam de um auxilio para poder ter o mínimo possível de dignidade e alimentação (g5).

Quando o benefício é citado como uma “ajuda”, corroba achados na literatura, como no estudo do Ministério do Desenvolvimento Social, ${ }^{47,49}$ no qual se pode observar a fala de agentes governamentais que acreditam que o beneficio seja uma dádiva aos beneficiários e não um direito. Dessa forma, as condicionalidades aparecem como uma obrigação a ser realizada pelos beneficiários por receberem uma "ajuda" do governo.

Na mesma direção, Costa et al. ${ }^{50}$ mostram que os beneficiários do programa também fazem uso do termo "ajuda" para fazer menção à caridade, subentendendo que o valor recebido advém da caridade do governo em garantir o acesso a itens básicos, como vestimenta e alimentação, ou seja, reafirmando a percepção do programa não como direito.

Entende-se que para a continuidade do benefício seja necessário cumprir as condicionalidades, isso aparece tanto na literatura como na percepção dos gestores, em especial quanto à frequência escolar, à carteirinha de vacinação e ao pré-natal, citados como as principais do programa, e as com maior frequência de acompanhamento. ${ }^{43,51}$ Entretanto, para autores como Pires, ${ }^{52}$ as condicionalidades, como a frequência escolar, não garantem por si só uma condição de maior mobilidade social aos beneficiários do PBF, quando não levam em conta a qualidade dos serviços oferecidos. 


\section{Considerações finais}

O perfil dos beneficiários do PBF confirma os achados na literatura, reafirmando que os objetivos do programa em atender às famílias em situação de maior vulnerabilidade se concretizam. No entanto, não existe o acesso dos serviços a informações unificadas sobre os beneficiários.

Observou-se que não existem ações e/ou mecanismos intersetoriais sendo construídos nem tampouco voltados especificamente para beneficiários do PBF. As ações têm se restringido ao acompanhamento setorizado das condicionalidades do programa. Entretanto, as chamadas "reuniões de território" parecem ser uma tentativa potente, mesmo considerando os empecilhos estruturais para a participação de todos os setores.

Por meio dessas reuniões seria possível tratar de assuntos voltados aos beneficiários do programa, além de planejar e realizar ações intersetoriais nesse território. Todavia, para que isto ocorra é necessário um investimento de todos os setores, repensando a política das ações realizadas pelos serviços, considerando a intersetorialidade como eixo estratégico, não só de otimização de recursos financeiros, estruturais e humanos, mas também de aprimoramento de competências, de aperfeiçoamento e intensificador de processos de trabalho compartilhados, e fortalecedor da rede pública de atenção à população.

A falta de dados consolidados e unificados entre os setores também foi identificada como um obstáculo para a realização de ações intersetoriais nesse território. Como medida para a unificação dos dados, sugere-se a criação de um sistema de informação, para além do Cadúnico, que pudesse ser acessado por todos os setores, incluindo dados de monitoramento, que permitam também processos de avaliação. Este sistema auxiliaria no trabalho em rede e na efetivação de ações intersetoriais no território, inclusive ações promotoras de SAN, podendo contribuir diretamente na consolidação do SISAN no município.

A percepção dos gestores sobre o programa é de que ele cumpre seus objetivos principais, na medida em que estes percebem que ele possibilita melhora da renda e das condições de vida das famílias, no entanto, ainda é visto como um "auxílio" aos beneficiários, e não como um direito.

Considerando que Santos tem como característica ser uma das cidades mais ricas do país, investimentos em políticas intersetoriais, que se traduzam em ações que melhorem as condições de trabalho para os gestores dos serviços e suas equipes, e em melhores condições de vida e saúde para a população, parecem ser um bom caminho, não só para qualificar os serviços e suas ações, mas também como uma forma de compartilhamento desta riqueza com a população local. 


\section{Agradecimentos}

Agradecemos aos gestores da Saúde, Educação e Assistência Social dos morros Nova Cintra, Vila Progresso e Santa Maria do Município de Santos/SP, pela participação no estudo em questão.

\section{Referências}

1. Brasil. Ministério do Desenvolvimento Social e Combate à Fome. Conselho Nacional de Segurança Alimentar e Nutricional. III Conferencia Nacional de Segurança Alimentar e Nutricional: por um desenvolvimento sustentável com soberania e segurança alimentar e nutricional; 03-06 jul. 2007; Fortaleza, CE. Brasília: CONSEA/MDS; 2007.

2. Brasil. Ministério do Desenvolvimento Social e Combate à Fome. Bolsa Família: uma década de resultados para a cidadania [Internet]. 07 ago. 2013. [acesso em: 13 set. 2014]. Disponível em: http:// bolsafamilia10anos.mds.gov.br/node/124

3. Brasil. Ministério do Desenvolvimento Social e Combate à Fome. Segurança Alimentar e Nutricional: trajetória e relatos da construção de uma política Nacional. Brasília: MDS; 2008. 86 p.

4. Sousa PA. Um marco na consolidação do estado de bem-estar brasileiro. Parte 1, Parte 2. Rio de Janeiro: IBASE; 2008.

5. Brasil. Ministério do Desenvolvimento Social e Combate à Fome. Sistema Nacional de Segurança Alimentar e Nutricional. Documento para subsidiar os Encontros Regionais de Gestores de SAN. Brasília: SISAN, MDS; 2010.

6. Brasil. Decreto no 7.272, de 25 de agosto de 2010. Regulamenta a Lei no 11.3146, de 15 de setembro de 2006, que cria o Sistema Nacional de Segurança Alimentar e Nutricional - SISAN com vistas a assegurar o direito humano à alimentação adequada, institui a Política Nacional de Segurança Alimentar e Nutricional - PNSAN, estabelece parâmetros para elaboração do Plano Nacional de Segurança Alimentar e Nutricional, e dá outras providências. Legislação Federal. Diário Oficial da União 28 ago. 2010.

7. Brasil. Lei No 11.346 , de 15 de setembro de 2006 que cria o Sistema Nacional de Segurança Alimentar e Nutricional - SISAN com vistas em assegurar o direito humano à alimentação adequada e dá outras providências. Diário Oficial da União 18 set. 2006.

8. Yazbek MC. Pobreza no Brasil contemporâneo e formas de seu enfrentamento. Serv. Soc. Soc. 2012; 110:288-322.

9. Albuquerque MC. Participação popular em políticas públicas: espaço de construção da democracia brasileira. São Paulo: Instituto Pólis; 2006. 124 p.

10. Brasil. Ministério do Desenvolvimento Social e Combate à Fome. Bolsa Família - Condicionalidades. [acesso em: 03 jun. 2014]. Disponível em: http://mds.gov.br/assuntos/bolsa-familia/gestao-doprograma/condicionalidades 
11. Coelho AVAG. A construção da intersetorialidade no Programa Bolsa Família em Manguinhos, no Rio de Janeiro [dissertação]. [Rio de Janeiro]: Fundação Oswaldo Cruz, Escola Nacional de Saúde Pública Sergio Arouca; 2009.

12. Junqueira LAP. Novas formas de gestão na saúde: descentralização e intersetorialidade. Saúde Soc. 1997; 6(2):31-46.

13. Junqueira LAP, Inojosa RM, Komatsu S. Descentralização e intersetorialidade na gestão pública municipal no Brasil: a experiência de Fortaleza. XI Concurso de Ensayos del CLAD "El tránsito de la cultura burocrática al modelo de la gerencia pública: perspectivas, posibilidades y limitaciones". Caracas: CLAD; 1997. 75 p.

14. Brasil. Conselho Nacional dos Direitos da Criança e do Adolescente. Construindo a Política Nacional dos Direitos Humanos de Crianças e Adolescentes e o Plano Decenal dos Direitos Humanos de Crianças e Adolescentes 2011/2020. Documento preliminar para consulta pública. [acesso em: 17 maio 2014]. Disponível em: http://www.unicef.org/brazil/pt/PoliticaPlanoDecenal_ConsultaPublica.pdf

15. Brasil. Decreto 5.209, de 17 de setembro de 2004. Regulamenta a Lei n0 10.836, de 9 de janeiro de 2004, que cria o Programa Bolsa Família, e dá outras providências. Diário Oficial da União 20 set. 2004.

16. Monnerat GL. Transferência condicionada de renda e saúde: lições do Programa Bolsa Família [Internet]. V Jornada Internacional de Políticas Públicas; 23-26 ago. 2011; São Luis, MA. UFMA; 2011. [acesso em: 14 set. 2016]. Disponível em http://www.joinpp.ufma.br/jornadas/joinpp2011/ CdVjornada/JORNADA_EIXO_2011/DESIGUALDADES_SOCIAIS_E_POBREZA/ TRANSFERENCIA_CONDICIONADA_DE_RENDA_E_SAUDE_LICOES_DO_ PROGRAMA_BOLSA_FAMILIA.pdf

17. Campelo T, Néri MC. Programa Bolsa Família: uma década de inclusão e cidadania. Brasília: Ipea; 2014. 87 p.

18. Coelho AVAG, Ferreira MN, Magalhães R. A intersetorialidade no Programa Bolsa Família: reflexões a partir de uma experiência local [Internet]. [acesso em: 25 jun. 2014]. Disponível em: http://www. ipc-undp.org/publications/mds/25M.pdf

19. Instituto Brasileiro de Geografia e Estatística. Cidades - Santos [Internet]. [acesso em: 17 maio 2014]. Disponível em: http://cidades.ibge.gov.br/xtras/perfil.php?lang=\&codmun=354850\&searc $\mathrm{h}=$ sao-paulo

20. Instituto Brasileiro de Geografia e Estatística. Cidades - Produto Interno Bruto, São Paulo Santos [Internet]. [acesso em: 06 jan. 2016]. Disponível em: http://cidades.ibge.gov.br/xtras/temas. php?codmun $=354850 \&$ \&idtema $=103$

21. Fundação Sistema Estadual de Análise de Dados. Mortalidade infantil em São Paulo [Internet]. [acesso em: 06 jan. 2016]. Disponível em: http://produtos.seade.gov.br/produtos/mortinf/

22. DATASUS. Relatório consolidado do Programa Bolsa Família: informes gerais sobre famílias. $2^{\mathrm{a}}$ Vigência de 2015. [acesso em: 06 jun. 2016]. Disponível em: http://bolsafamilia.datasus.gov.br/w3c/ consol_estado_consol_bfa.asp?uf=SP\&vigencia=30\&gru=2T\&ne=1\&desvig=\&tipo_rel=\&brsm=1

23. DATASUS. Relatório geral de ocorrências [Internet]. [acesso em: 06 jan. 2016]. Disponível em: http:// bolsafamilia.datasus.gov.br/w3c/bfa_relconsol.asp 
24. DATASUS. Relatório consolidado do Programa Bolsa Família. Percentual de cobertura com base nas famílias totalmente acompanhadas [Internet]. [acesso em: 06 jan. 2016]. Disponível em: http:// bolsafamilia.datasus.gov.br/w3c/consol_uf_cobertura_bfa.asp?gru $=5 \& u f=S P \& v i g e n c i a=30 \& c o b$ $=1 \&$ brsm $=1 \&$ regional $=00$

25. Fundação Sistema Estadual de Análise de Dados - SEADE. Índice paulista de vulnerabilidade social: versão 2010 [Internet]. [acesso em: 13 jun. 2016]. Disponível em: http://indices-ilp.al.sp.gov.br/view/ pdf/ipvs/principais_resultados.pdf

26. Santos. Prefeitura Municipal de Santos. Endereços das Unidades [Internet]. [acesso em: 12 dez. 2015]. Disponível em: http://www.santos.sp.gov.br/aprefeitura/secretaria/saude/enderecos-das-unidades

27. Santos. Prefeitura Municipal de Santos. Secretaria de Educação. [acesso em: 12 dez. 2015]. Disponível em: http://www.portal.santos.sp.gov.br/seduc/page.php?7

28. Yin RK. Case study research: design and methods. California: Sage Publications Inc.; 1989.

29. Ventura MM. O estudo de caso como modalidade de pesquisa. Rev. SOCERJ 2007; 20(5):383-386.

30. Bonoma TV. Case research in marketing opportunities: problems and process. Journal of Marketing Research 1985; 22(2):199-208.

31. Minayo MCS. O desafio do conhecimento. Pesquisa qualitativa em saúde. 13 ed. São Paulo: Hucitec; 2013. 407 p.

32. Franco MLPB. Análise de conteúdo. Brasília: Plano; 2003. 72 p. Pesquisa em Educação.

33. Martins MCFN, Bógus CM. Considerações sobre a metodologia qualitativa como recurso para o estudo das ações de humanização em saúde. Saúde Soc. 2004; 13(3):44-57.

34. Coronel DA, Amorim AL, Bender Filho R, Sousa EP. Métodos qualitativos e quantitativos em pesquisa: uma abordagem introdutória. In: Lana RP. organizador. Multifuncionalidades sustentáveis no campo: agricultura, pecuária e florestas. Viçosa-MG: Arka; 2013. p. 40-60.

35. Guimarães JAC. A dimensão teórica do tratamento temático da informação e suas interlocuções com o universo científico da International Socity for Knowledge Ornanization (ISKO). Revista Iberoamericana de Ciência da Informação (RICI), 2008; 1(1):77-99.

36. Minayo MCS. Pesquisa social: teoria, método e criatividade. 24 ed. Petrópolis: Vozes; 1994. p. 70-76.

37. Cavalcante RB, Calixto P, Pinheiro MMK. Análise de conteúdo: considerações gerais, relações com a pergunta de pesquisa, possibilidades e limitações do método. Inf. Soc.: Est. 2014; 1:13-18.

38. Bardin L. Análise de conteúdo. Lisboa: Edições 70, LDA; 2009.

39. Scarpellini M, Carlos VY. Monoparentalidade feminina e vulnerabilidade social: a realidade de mulheres chefes de família no município de Apucarana. Anais II Simpósio Gênero e Políticas Públicas; 18-19 ago. 2011. Londrina: Universidade Estadual de Londrina; 2011. 11 p.

40. Atlas do Desenvolvimento Humano no Brasil. Santos, SP [Internet]. [acesso em: 17 jul. 2015]. Disponível em http://www.atlasbrasil.org.br/2013/pt/perfil_m/santos_sp

41. Saglio-Yatzimirsky MC. Políticas urbanas, territórios e exclusão social: as favelas nas grandes cidades - Brasil e Índia. Estud. Av. 2009; 23(66):219-222. 
42. Junqueira LAP. Novas formas de gestão na saúde: descentralização e intersetorialidade. Saúde Soc. 1997; 6(2):31-46.

43. Licio EC, Mesquita CS, Curralero CRB. Desafios para a coordenação intergovernamental do Programa Bolsa Família. Rev. Adm. Empres. 2011; 51(5):458-470.

44. Magalhães R, Burlandy L, Senna M, Schottz V, Scalercio G. A implementação do programa Bolsa Família: as experiências de São Francisco de Itabapoana e Duque de Caxias. Ciênc. Saúde Coletiva 2007; 12(6):1513-1524.

45. Genevois MLBP, Costa OV. Carência habitacional e déficit de moradias: questões metodológicas. São Paulo Perspec. 2001; 15(1):73-84.

46. Pettengill MAM; Angelo M. Vulnerabilidade da família: desenvolvimento do conceito. Rev. Latinoam Enfermagem 2005; 13(6):982-88.

47. Brasil. Ministério da Saúde. O SUS no seu município, garantindo saúde para todos. Brasília: Ministério da Saúde; 2004. Série B. Textos Básicos de Saúde.

48. Santos CRB, Magalhães R. Pobreza e política social: a implementação de programas complementares do Programa Bolsa Família. Ciênc. Saúde Coletiva 2012; 17(5):1215-1224.

49. Brasil. Ministério do Desenvolvimento Social e Combate à Fome. O Programa Bolsa Família e o enfrentamento das desigualdades de gênero. Brasília: AGENDE; 2006. [acesso em: 14 set. 2016]. Disponível em: http://www.ipc-undp.org/doc_africa_brazil/Webpage/missao/Pesquisas/ PESQUISA_MULHER.pdf

50. Costa VM, Castro LMC, Prado SD, Gugelmin SA. A “ajuda” do programa bolsa família: representações da transferência de renda para seus beneficiários. Demetra 2012; 7(3):203-216.

51. Silva MOS. O Bolsa Família: problematizando questões centrais na política de transferência de renda no Brasil. Ciênc. Saúde Coletiva 2007; 12(6):1429-1439.

52. Pires A. Afinal, para que servem as condicionalidades em educação no Programa Bolsa Família? Ensaio: Aval. Pol. Públ. Educ. 2013; 21(80):513-532. 
